\title{
PERCURSOS DE LEITURA EM BAUDRILLARD E PÊCHEUX: O REAL, O SOCIAL, A LINGUAGEM E SUAS IMPLICAÇÕES NO TRABALHO COM A LÍNGUA - O NÃO APARAR DAS ARESTAS.
}

\section{LIMA, Vânia Carmem - Mestre em Lingüística/UFU - Docente CAJ/UFG - vaniacarmem@yahoo.com.br}

RESUMO: Este artigo é resultado de reflexões acerca das teorias de Baudrillard e Pêcheux ao tratarem o real, o social e a linguagem, sob perspectivas diferentes, o que pode trazer implicações no trabalho com a língua em sala de aula, uma vez que tais elementos são constitutivos da realidade escolar. Nele também estão evidenciadas algumas práticas possíveis cuja fundamentação se apóia em um ou outro teórico, ainda que de forma inconsciente pelo professor.

PALAVRAS-CHAVE: Teorias de Baudrillard. Teorias de Pêcheux. Práticas de Sala de Aula

ABSTRACT: This article is the result of some reflections about Baudrillard's and Pêcheux theories who see "the real", "the social" and language through different perspectives, which might have consequences for the classroom work on language, since the elements mentioned above form the school reality. Some new practice (underpinned by Baudrillard and Pêcheux) is also shown, although the teacher is not aware of that.

KEY-WORDS: Baudrillard's theories, Pêcheux's theories, classroom practice.

\author{
Quadro nenhum está acabado \\ Disse certo pintor; \\ Se pode sem fim continuá-lo, \\ Primeiro, ao além de outro quadro \\ Que, feito a partir de tal forma, \\ Tem, na tela, oculta, uma porta \\ Que dá a um corredor \\ Que leva a outra \\ E muitas outras \\ João Cabral de Melo Neto
}

Introdução

O presente trabalho tem como propósito trazer à discussão as idéias ou teorias de Jean Baudrilhard e de Michel Pêcheux, tratadas em A sombra das maiorias silenciosas; Delimitações, inversões e deslocamentos; Semântica e discurso (anexo III); e, porque não, Estrutura ou acontecimento. 
Numa discussão teórica, teceremos algumas considerações acerca das posições dos autores em relação ao real, ao social, à linguagem e as implicações desses elementos no âmbito escolar, considerados sob a óptica de um ou outro autor.

Desse modo, deixamos evidenciar, neste trabalho, os pontos de aproximação, se é que existem, e os pontos de distanciamento entre os autores, em relação às temáticas por eles abordadas bem como os reflexos dessas formas de pensar os elementos: o real, o social e a linguagem na escola em que tais fatores constituem também a realidade escolar, sem, contudo, impedir o percurso pelo que reclamam os temas e as teorias.

\section{Discussão sobre o tema}

Percursionar na leitura das idéias de Jean Baudrillard e de Pêcheux é caminhar nos interstícios de conceitos e visões diferenciados de mundo, de linguagem, de sistemas; é fazer com que o constatado não seja jamais sedimentado, mas, ao contrário, revisitado, redimensionado, visto por outras lentes que não refletem, mas refratam a realidade, até porque não chegamos ao real senão mediatizados pelo simbólico. Tanto assim que Pêcheux traz à discussão ou para discursividade o enunciado: "Ganhamos", cuja estrutura deixa espaços vazios, tais como - “Quem ganhou?", “Ganhou o quê? Apontando, assim, para o acontecimento atualizado, não repetível, cujos efeitos de sentido se dão na conjunção: estrutura/ acontecimento. Dito de outra forma, as lacunas do dizer evidenciadas no enunciado - "Ganhamos" - faz emergi-lo numa rede de associações implícitas - paráfrases, alusões, comentários - sem, no entanto, prendê-lo à estabilidade lógica. E essa atualização do acontecimento estruturado, o enunciado, falta, muitas vezes, ao trabalho com a língua na escola. Nesta, os enunciados são tomados, não raro, como estáveis, prontos, desconsiderando o processo de enunciação em que os enunciados emergiram. Ou seja, são ignoradas as condições de produção, suas filiações, o processo sócio-histórico do acontecimento, no que incluem os sujeitos falantes envolvidos no evento enunciativo.

Como afirma Pêcheux:

Não se trata de pretender aqui que todo discurso seria como um aerólito miraculoso, independente das redes de memória e dos trajetos sociais nos quais ele irrompe, mas de sublinhar que, só por sua existência, todo discurso marca a possibilidade de uma desestruturaçãorestruturação dessas redes e trajetos...(1990 a p. 56). 
Nesse sentido, todo discurso se constitui no entrecruzamento dos efeitos de filiações, de memória fazendo da língua histórica, com possibilidade de deslocamento, sendo atravessado pelas determinações inconscientes, o que ressoa na voz de Pêcheux:

(...) não há identificação plenamente bem sucedida, isto é, ligação sócio-histórica que não seja afetada, de uma maneira ou de outra, por uma infelicidade...(1990 a p.56).

É nesse sentido também que Orlandi (2001) diz que o funcionamento da linguagem se assenta na tensão - paráfrase/ polissemia - entre o dizível, o estabilizado e o deslocável. Em outras palavras, o que se diz já foi dito em outro lugar. Porém, na atualização desse dizer outros sentidos são construídos dado o processo de enunciação que atualiza o enunciado.

Como preconiza Foucault (1996:26), o novo não está no que é dito, mas no acontecimento de sua volta. Deste modo, o novo dizer se fez na ancoragem com o já dito (paráfrase) e ao seu ressurgimento outros sentidos são mobilizados, o que constitui, pois, a polissemia.

Pêcheux (1990b), assim, trabalha o lugar da discursividade. Lugar em que se vê a relação da língua com a ideologia, pois o discurso materializa a ideologia e esta materialidade é decorrente da articulação da língua com a história, articulação esta constitutiva do sujeito e do sentido.

Desta forma, o sujeito não poderia ser a origem de si. Como nas palavras de

Orlandi,

Pelo deslocamento proposto por M. Pêcheux (1975), fazendo intervir a ideologia na relação com a linguagem, o teatro da consciência (eu vejo, eu penso, eu falo, eu te vejo etc.) é observado dos bastidores, lá de onde se pode captar que se fala ao sujeito, que se fala do sujeito, antes de que o sujeito possa dizer: "eu falo" (2002, p. 66-67).

Isto se configura na ilusão das evidências subjetivas do sujeito como idêntico a si mesmo, ilusão, aliás, necessária uma vez que necessitamos da ilusão de um mundo homogeneamente lógico e essa logicidade passa pela questão de o sujeito se considerar centro, origem de si, fonte de seu dizer. Nesse sentido, conforme D. Maldidier (1990), essa primeira evidência é colocada em relação com as "famílias parafrásticas", constitutivas dos efeitos de sentido. 
Correlativa a esta evidência, outra evidência se faz necessária - a evidência do sentido ou ilusão da literalidade. Estas evidências constituem, respectivamente, o que Pêcheux e Fuchs $(1975)^{1}$ denominam de esquecimento $n^{\circ} 1$ e esquecimento $n^{\circ} 2$, através do que o sujeito cria uma realidade discursiva ilusória. Segundo D. Maldidier (op. cit.), a zona onde agem esses esquecimentos se configura da relação: o pré-construído (já dito) para o esquecimento $\mathrm{n}^{\mathrm{o}} 2$; o inconsciente para o esquecimento $\mathrm{n}^{\mathrm{o}} 1$.

Se no trabalho com a linguagem não se considera as implicações desses esquecimentos, ao se trabalhar, por exemplo, o texto, na sua modalidade oral ou escrita, correse o risco de tomar os sentidos como únicos e dados a priori no texto (cf. Koch, 1998), desconsiderando o fato de que esses sentidos são construídos a partir das pistas deixadas no texto pelo seu produtor, da forma como se diz aquilo que é dito, pois o modo de dizer não é indiferente aos sentidos, e das experiências histórico-sociais do leitor, no que inclui seu histórico de leitor. É a evidência do sentido ou ilusão da literalidade - esquecimento $\mathrm{n}^{\mathrm{o}} 2$, que é da ordem da enunciação. Esse esquecimento produz em nós a impressão de que há uma relação direta entre o pensamento, a realidade e o mundo.

Da mesma forma, se se desconsiderar o fato de que todo texto tem relação com outros textos, de que todo discurso se faz no interdiscurso, ou seja, se negar a premissa de que nenhum discurso é original, ignorando o seu caráter heterogêneo e a sua condição de poder ser dito, redito e estar ainda por dizer, conforme Lima (2001), está se fazendo do texto uma ilha e do aluno-leitor um ilhado na sua interpretação e compreensão textuais. Está posto aqui, portanto, a evidência de sujeito idêntico a si mesmo, fonte do seu dizer-esquecimento $\mathrm{n}^{\mathrm{o}}$ 1, que é da ordem do inconsciente e resulta do modo pelo qual somos afetados pela ideologia.

Pode-se dizer que é por meio da ideologia, ao interpelar o indivíduo em sujeito, que este se submete à língua significando e significando-se pelo simbólico na história. É preciso, pois, que algo do mundo ressoe no "teatro da consciência" do sujeito para que produza sentido, e isso é o que abre para a possibilidade de interpretação, pois a ideologia é a própria possibilidade de interpretação. Assim, não escapamos à ideologia, já que estamos o tempo todo interpretando as coisas, o mundo. Porém, a interpretação não constitui apenas em um gesto de decodificação ou apreensão dos sentidos. Ela não se apresenta livre de determinações. Assim, não pode ser qualquer interpretação, pois é desigualmente distribuída na formação social. Ela é garantida sob dois aspectos pela memória: a memória institucionalizada (o arquivo), que constitui o trabalho social da interpretação separando quem

\footnotetext{
${ }^{1}$ Apud Brandão (1995).
} 
Ztinerarius

eflectionis
Revista Eletrônica de Educação do Curso de Pedagogia do Campus Avançado de Jataí da Universidade Federal de Goiás [Vol I - n.2 ] [jan/jul] [ 2006 ]

tem e quem não tem direito a ela, e a memória constitutiva (o interdiscurso), que constitui o trabalho histórico da constituição dos sentidos. Desse modo, o gesto de interpretação tanto pode estabilizar como deslocar sentidos, conforme Orlandi (2001).

Concordando com Pêcheux (1995), podemos afirmar que o "sentido" é produzido no "non-sens" pelo deslocamento do significante ou processo metafórico, porém esse deslizamento não desaparece sem deixar traços no sujeito - ego da "forma-sujeito ideológica” como evidência de um sentido. É, pois, a interpelação ideológica posta como ritual e, como tal, há de se considerar que não há ritual sem falhas, sem brechas, pois o sujeito não pode ser pensado como unidade de uma interioridade, como uno. Ele é dividido como sujeito que cometeu um lapso: não foi ele que o cometeu, ele apenas disse uma palavra por outra. É o um se dividindo em dois, no imaginário é um, mas se transforma em dois.

Vejamos como isso se dá: em um primeiro momento, temos a interpelação do indivíduo em sujeito pela ideologia quando este, afetado pelo simbólico, na história, tornase sujeito, subjetiva-se, sendo, ao mesmo tempo, despossuído e mestre do que diz. Esta é uma forma-sujeito histórica, com sua materialidade. Uma vez constituído sujeito, desencadeia-se outro processo - o estabelecimento e a transformação do estatuto do sujeito corresponde ao estabelecimento e à transformação das formas de individualização do sujeito em relação ao Estado. Noutras palavras, cabe ao Estado com suas instituições individualizar a forma-sujeito histórica, produzindo diferentes efeitos nos processos de identificação.

O indivíduo, uma vez sujeito, determina-se pela forma concreta como, na história, terá sua individualização - no caso do sistema capitalismo, a forma indivíduo livre e responsável deve responder como sujeito jurídico (de direitos e deveres), frente ao Estado e aos outros homens.

Desse modo, a questão do sujeito, da ideologia, e da resistência deve ser vista como aquilo que foge à vontade do sujeito. O sujeito, por exemplo, não se torna livre por falta de vontade, somos condicionados sócio-historicamente. Somos seres sociais e históricos, tal como a língua.

Nesse sentido, Pêcheux traz o social para a língua. Segundo ele,

- Não se há dominação sem resistência: primado prático da luta de classes, que significa que é preciso "ousar se revoltar".

- Ninguém pode pensar do lugar de quem quer que seja: primado prático do inconsciente, que significa que é preciso suportar o que venha a ser pensado, isto é, é preciso "ousar pensar por si mesmo"( Pêcheux, 1995, p. 304). 
Dito de outra forma, é preciso haver resistência, não para ir contra, mas para abrir novas possibilidades - primado $\mathrm{n}^{\mathrm{o}} 1$.

Ninguém pode pensar do lugar de quem quer que seja: cada qual fala e pensa do seu lugar e esse lugar é correlativo ao da estrutura social no qual se posiciona o sujeito e de onde ele fala - primado $\mathrm{n}^{\circ} 2$. Assim as mesmas expressões produzem sentidos diferentes dependendo de quem fala e do lugar de onde se fala.

Falando de outro lugar, Jean Baudrillard deixa o social fora da língua ou das questões discursivas e nega o social. Assim, conforme sua óptica, os sentidos independem de quem seja o falante e de sua posição. As palavras, para ele, não vêm carregadas de sentidos construídos em outros lugares nem tampouco adquirem novos sentidos num evento novo de fala ou acontecimento. Assim, em Baudrillard, a língua se apresenta externa ao indivíduo, imune às suas condições histórico-sociais, não sendo a língua considerada como processo e produto das interações humanas, condicionados que são os homens aos fatores sóciohistóricos. São suas as palavras:

Na verdade é isso que assistimos hoje: à desagregação do pensamento do social, ao definhamento e à involução do social, ao enfraquecimento do simulacro social, verdadeiro desafio ao pensamento construto e produtivo do social que nos domina. E isso de repente, como se o social nunca tivesse existido... Então não se pode mais dizer que o social morre, pois ele é desde sempre acumulação do morto. (Baudrillard, 1985, ps. 59-60).

Segundo Baudrillard, as massas são a impossibilidade de se ter o social e a política. A massa é o que resta quando se esqueceu tudo do social (op. cit., 1985, p.12).Aos olhos do autor, as massas são o sintoma de um social acabado que tem por característica a inércia, a apatia.

Assim, ele se mostra descrente em relação ao social e à política. Saudosista o tempo todo - vislumbrando o socialismo no "poder" - Baudrillard trabalha no plano da idealização, tendo por perspectiva um real idealizado. Segundo o autor, o socialismo modelo é diferente do socialismo histórico. Como mito, como força de ruptura, portanto histórico, o socialismo não tem tempo de se fortalecer como modelo, não é, pois, estável. Já hoje, o socialismo mostra-se como um modelo estável, confiável, porém, não mais se faz como exigência revolucionária, mas como simulação de mudança. Daí a razão da sua descrença em relação ao social e da sua não confiabilidade em relação à política. Desacreditando na força revolucionária, já que não se faz mais como exigência, as mudanças para ele não passam de simulacro do social. E, nesse sentido, o socialismo se apresenta como modelo estável e 
Ztinerarius

Peflectionis
Revista Eletrônica de Educação do Curso de Pedagogia do Campus Avançado de Jataí da Universidade Federal de Goiás [Vol I - n.2 ] [jan/jul] [ 2006 ]

ISSN: $1807-9342$

confiável. Acredita-se nas mudanças simuladas e, com isso, estabiliza-se o sistema e este se solidifica como modelo.

Baudrillard traz também à discussão o acontecimento tratado por Pêcheux: "Nós ganhamos", relativo à vitória eleitoral, na França. Entretanto, ele, diferentemente de Pêcheux, não trabalha tal acontecimento no plano também da sua estrutura ou plano discursivo. Isto é compreensível se considerarmos o fato de que Baudrillard, ao deixar o social fora da língua, toma o real como algo idealizado, pois ele ignora a conjunção estrutura/ acontecimento como produtora de sentidos e se atém apenas ao plano das idéias ou interpretação de conteúdo, desconsiderando a materialidade lingüística do enunciado. Entende-se por interpretação de conteúdo, conforme Orlandi (2001), aquelas interpretações cujos sentidos levantados do texto não se ancoram na sua materialidade lingüística.

Ocorre que esse tipo de interpretação é ainda muito recorrente nas aulas de leitura, na escola. Nessas aulas não raro o professor, procurando evitar o trabalho com a gramática normativa e isolada, ou fugindo à prática em que se toma o texto como pretexto para se trabalhar a gramática, conduz os alunos à interpretação de conteúdo, ou seja, trabalha as idéias de forma abstrata, sem se considerar a estrutura ou materialidade lingüística que geraram as idéias no texto. Assim, procura-se extrair sentidos dos textos, ao responder, por exemplo, à questão: o que quer dizer este texto? Como se a linguagem fosse transparente. A questão que deveria ser colocada então era: como este texto significa? O que remete ao "como" e não ao "o quê". Ao se indagar o que o texto quer dizer, ao invés de como ele produz o dizer, como ele significa, não se está atentando para os recursos lingüísticos mobilizados no texto, para o trabalho com o léxico e os efeitos de sentido decorrentes desse trabalho, pois, ao não se ancorar na materialidade da língua, qualquer interpretação é possível, é válida , como se não existissem os limites do sentido. Limites que se instauram pela materialidade lingüística. E aí o ideal pode assumir o lugar do real.

Desse modo, podemos dizer que Baudrillard distancia-se de Pêcheux e de Foucault, pois, ao tomar o real como algo idealizado, inexiste para Baudrillard o poder.

\section{Conclusão}

Dialogar com Jean Baudrillard e Pêcheux é situar-se no plano em que se concebe os conceitos, as teorias, os modos de pensar e de falar dos objetos e das coisas como em permanente percurso, não podendo jamais serem vistos como portos de ancoragem, mas 


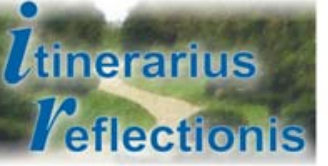

Revista Eletrônica de Educação do Curso de Pedagogia do Campus Avançado de Jataí da Universidade Federal de Goiás [Vol I - n.2 ] [jan/jul] [ 2006 ]

ISSN: $1807-9342$

como portos de passagem pelos quais novos teóricos poderão passar deixando suas marcas ao elaborarem seus construtos teóricos sobre temas já discutidos e teorizados.

A discussão teórica que fizemos aqui, neste trabalho, vem elucidar algumas das diferentes posições desses dois autores acerca de temas como: o real, o social, a linguagem. E, nesse sentido, o trabalho traz algumas das implicações desses temas com o trabalho com a linguagem em sala de aula. O que é deixado fora e o que é considerado no trato com a língua.

O primeiro autor se situa no plano da idealização, lugar de onde se vê e analisa os objetos de forma idealizada, sem tomá-los em sua dimensão real. Concordamos, porém, com Orlandi (1996) quando diz que apenas nos aproximamos do real, não chegando propriamente a ele, mediados que somos pelo simbólico. Contudo, não chegar ao real não significa ignorá-lo, mas considerá-lo. Quanto ao social, esse autor o tem como uma impossibilidade. E a razão dessa impossibilidade são as massas pois, segundo ele, as massas são a parte daquilo que restou quando o social está esquecido. Em relação à linguagem, podese dizer que, ao excluir dela o social, o autor deixou de tomá-la como fruto do trabalho humano. E, nesse sentido, a linguagem passa a se situar no plano do ideal, sendo desconsiderada a língua enquanto materialidade. Materialidade esta que se faz da articulação estrutura / acontecimento.

O segundo autor se situa no plano da materialidade, do discursivo. E, nesse sentido, tanto a estrutura como o acontecimento são igualmente considerados. A linguagem é assim concebida enquanto processo que comporta o enunciado e a enunciação. E, nesse sentido, a língua é tomada como histórica, se historicizando com os sujeitos que se deslocam e fazem deslocar os sentidos pelos efeitos da memória (interdiscurso), dos equívocos, da incompletude da linguagem e dos sentidos. É o que constitui o binômio paráfrase/ polissemia sobre o qual se assenta a linguagem e que faz dela inacabada, sempre em processo, fazendo-se num percurso histórico, ao mesmo tempo que faz a história do homem. No que se refere ao social, Pêcheux o considera como fazendo parte da língua, uma vez que esta nasce da interação entre os homens e estes fazem parte do social e ocupam, portanto, lugares diferentes na escala social. Estes lugares, porém, passam a posições quando se trata do processo discursivo. Pois, neste processo o sujeito não ocupa lugares, mas posições no discurso, posições estas correlatas aos lugares na estrutura social. Dito de outro modo, a projeção da sua situação (lugar no mundo) para sua posição no discurso transforma a situação social (empírica) em posição sujeito (discursiva). Assim, o aluno pode falar do lugar do professor, o 
Utinerarius

Peflectionis
Revista Eletrônica de Educação do Curso de Pedagogia do Campus Avançado de Jataí da Universidade Federal de Goiás [Vol I - n.2 ] [jan/jul] [ 2006 ]

ISSN: $1807-9342$

empregado do lugar do patrão, assumindo tais posições no discurso Orlandi (2001). Nesses termos, o real ganha existência e seu lugar não pode ser ignorado, na visão de Pêcheux.

E assim, podemos dizer que esses dois autores se aproximam no que se refere à abordagem das mesmas temáticas e se distanciam na forma como analisam tais temas e no modo como os concebem.

Assim também nós, professores, podemos nos aproximar quanto aos temas trabalhados em sala, quanto a vontade de acertar, mas nos distanciarmos na forma de abordagem desses temas, em decorrência da maneira como os concebemos. Portanto, ao se trabalhar com a linguagem, o professor deve ter claro a sua concepção de língua e linguagem e de sujeito aprendiz. Este que é um ser social, que se interage através dessa linguagem, construindo identidades e assumindo lugares no palco da vida. Entretanto, essa assumência não é automática, pois não há poder sem resistência e, através da resistência desse sujeito, novos lugares podem ser materializados, conforme o que preconiza o primado $\mathrm{n}^{0} 1$, citado anteriormente - resistir não é ir contra, mas abrir novas possibilidades. Também no discurso não há posições estabilizadas. $\mathrm{O}$ sujeito pode assumir nele diferentes posições e a isso denominamos formação discursiva. Dependendo, pois, da posição daquele que profere a palavra, esta muda de sentido. Assim, pode-se dizer que os sentidos não vêm inscritos nas palavras. Os sentidos são derivados das formações discursivas em que se inscrevem as palavras. Desse modo, o discurso se constitui em seus sentidos porque aquilo que o sujeito diz se inscreve em uma formação discursiva.

Portanto, tomar o texto no seu processo discursivo significa considerar as formações discursivas de onde derivam os sentidos das palavras e de onde fala o sujeito e considerar também as condições de produção que constituem os discursos. Conforme Orlandi (2001), estas condições funcionam segundo os seguintes fatores: a) a relação de sentidos, que significa que todo discurso se relaciona com outros discursos; b) o mecanismo da antecipação, segundo o qual o sujeito tem a capacidade de colocar-se no lugar do seu interlocutor e, com isso, adequar a sua fala, no que incluem os recursos argumentativos; c) a relação de forças que aponta para a questão da posição do sujeito no discurso. Segundo essa noção, a posição que assume o sujeito ao dizer é constitutivo do que ele diz. Todos esses mecanismos de funcionamento do discurso constituem o que chamamos formações imaginárias. Desse modo, o funcionamento do discurso não se dá com os sujeitos físicos nem com os seus lugares empíricos, mas com as suas imagens, resultantes de projeções. Essa projeções, aliás, é que permitem a passagem dos lugares (empíricos) dos sujeitos para posições no discurso. Nessa 
perspectiva, não se procura no texto o seu sentido verdadeiro, mas o real do sentido em sua materialidade lingüistica e histórica (Orlandi, 2001, p.59).

Referências Bibliográficas

BAUDRILLARD, Jean. À sombra das maiorias silenciosas- o fim do social e o surgimento das massas. São Paulo: editora brasiliense, 8 ed., 1985.

BRANDÃO, Helena H. Nagamine. Introdução à análise do discurso. 4ed. Campinas, SP: editora da Unicamp, 1995.

D. MALDIDIER, P. “(Re)Ler Michel Pêcheux Hoje”. In: L'inquietude du discours. Paris:

Ed. Des Cendres, 1990.

FOUCAULT, M. A ordem do discurso. São Paulo: Edições Loyola, 1996.

KOCH, Ingedore Villaça. O texto e a construção dos sentidos. São Paulo: Contexto, 1998.

LIMA, Vânia Carmem. Heterogeneidade discursiva em Relato de um certo Oriente: unidade na dispersão. Dissertação de Mestrado. Instituto de Letras e Lingüística: Universidade Federal de Uberlândia: Uberlândia/MG, 2001.

MELO NETO, João Cabral de. Os melhores poemas de João Cabral de Melo Neto/ seleção de Antônio Carlos Secchin, 4 ed. São Paulo: Global, 1994.

ORLANDI, Eni P. Língua e conhecimento lingüístico: para uma história das idéias no Brasil. São Paulo: Cortez, 2002. Análise do discurso: princípios e procedimentos. Campinas, SP: Pontes, 3ed. 2001. Interpretação. Vozes: Rio de Janeiro, 1996.

PÊCHEUX, M. O discurso: estrutura ou acontecimento. Campinas: Pontes, 1990 . "Delimitações, inversões, deslocamentos" In ORLANDI, Eni ORLANDI \& GERALDI, João Wanderley (org.). Cadernos de estudos lingüísticos. Campinas: Universidade Estadual de Campinas, 1990b.

Semântica e discurso: uma crítica à afirmação do óbvio. Campinas: Editora da UNICAMP, 1995. 
Revista Eletrônica de Educação do Curso de Pedagogia do Campus Avançado de Jataí da Universidade Federal de Goiás [Vol I - n.2 ] [jan/jul] [ 2006 ]

ISSN: 1807-9342 